\title{
Capital social e a participação dos usuários do SUAS no Rio Grande do Sul: um estudo de política pública'
}

\author{
Douglas Marques \\ Universidade Estadual de Maringá (UEM) - Maringá - Paraná - Brasil \\ ORCID: https://orcid.org/0000-0001-9679-7584 \\ Everton Rodrigo Santos \\ Universidade Feevale - Novo Hamburgo - Rio Grande do Sul - Brasil \\ ORCID: http://orcid.org/0000-0002-6270-1465
}

\section{Resumo}

O presente artigo baseia-se na teoria do capital social de Putnam e sua relação com o aspecto da participação nas políticas públicas, no Rio Grande do Sul, em especial nas cidades de Caxias do Sul e de Novo Hamburgo. Pretendemos demonstrar, comparativamente, a relação entre o acúmulo capital social e a qualidade da participação nas políticas públicas através de pesquisa de opinião pública, tipo Survey, nas cidades em tela, totalizando 382 questionários aplicados diretamente aos usuários do Sistema Único de Assistência Social (SUAS). Neste sentido, por meio deste estudo, podemos afirmar estatisticamente que na medida em que cresce o estoque de capital social, cresce a participação no âmbito das políticas públicas.

Palavras-chave: Capital Social. Políticas Públicas. Participação. Rio Grande do Sul.

Social capital and the participation of the Unified System of Social Assistance' users of the Rio Grande do Sul state: a study of public policy

\section{Abstract}

The present study is based on theory of social capital and its impact related to the participation aspects of the public policy, in Rio Grande do Sul state, especially in the Caxias do Sul and Novo Hamburgo cities. In this way, we intend to demonstrate comparatively the relationship between the accumulation of social capital and the quality of participation in the public policy. Regarding the methodological delimitation, we used a survey research and 382 questionnaires were directly applied to Unified System of Social Assistance' users. In this sense, it was possible to affirm our hypothesis, that there is a positive relationship between social capital and the quality of participation in the public policy, thus, us to affirm

\footnotetext{
${ }^{1}$ Agradecemos aos pareceristas pelas pertinentes críticas ao nosso artigo.
} 
that in so far as the stock of social capital grows, also occurs the growth of participation in the public policy.

Keywords: Social Capital. Public policy. Participation. Rio Grande do Sul.

\section{Capital Social y la participación de los usuarios de Asistencia social pública brasileña en Rio Grande do Sul: un estudio de política pública}

\section{Resumen}

El presente artículo se basa en la teoría de capital social y su impacto en los aspectos de la participación en las políticas públicas en Rio Grande do Sul, especialmente en las ciudades de Caxias do Sul y de Novo Hamburgo. La pretensión es relacionar la asociación existente en capital social y la calidad de la participación en las políticas públicas. Se utilizó de encuesta de opinión pública, tipo Survey, totalizando 382 cuestionarios aplicados directamente a los usuarios del Asistencia social pública brasileña. En este sentido, estadísticamente fue posible afirmar nuestra hipótesis, cuál es, que existe relación positiva entre capital social y la calidad de la participación en las políticas públicas, así, en la medida en que crece la cantidad del capital social, crece la participación en el ámbito de las políticas públicas.

Palabras clave: Capital Social. Políticas públicas. Participación. Río Grande do Sul.

\section{Introdução}

O recente relatório da revista The Economist aponta para o declínio dos governos democráticos no mundo nos últimos anos, considerando que apenas $5 \%$ da população vive em uma "democracia plena". Acompanhando esta tendência, o Brasil foi classificado no nível mais baixo de "democracias com falhas" por um lado, se o ideal de uma sociedade democrática seria formado por um conjunto de leis e instituições fortes (NORTH, 2007). Por outro lado, se a sociedade democrática seria sustentada pela confiança e pelo envolvimento cívico do cidadão (PUTNAM, 2000; BAQUERO, 2013).

Quando analisamos as políticas públicas na atualidade, sendo aquelas pelas quais os governos traduzem seus propósitos em programas e ações, que produzirão resultados ou as mudanças desejadas no mundo real (SOUZA, 2006), constata-se um grande desafio por parte dos governos, que precisam responder às demandas sociais, articulando recursos escassos. Nessa direção, aliado às instituições políticas, o capital social (PUTNAM, 2000), enquanto confiança interpessoal, participação em grupos e associações e envolvimento cívico, poderia ser um importante vetor para a estabilidade da democracia e o enfrentamento das desigualdades sociais, influenciando positivamente, entre outros aspectos, na qualidade da participação da sociedade nas instituições do Estado.

Muito embora nas últimas décadas a sociedade brasileira tenha experimento um crescimento significativo da descentralização de políticas públicas, persistem ainda os dilemas para que essas políticas estejam de fato voltadas para o

${ }^{2}$ Em 2014 a pontuação do Brasil era de 7.38 para um máximo de 10. Em 2017, a pontuação caiu para 6.86, ficando perto de um regime considerado híbrido. Disponível em: http://economistbrazil.com.br/pt_br/Noticias.aspx?id=2. Acesso em 13 de mar. 2018. 
Capital social e a participação dos usuários do SUAS no Rio Grande do Sul: um estudo de política pública.

aprofundamento da democracia e da participação da sociedade. Num primeiro momento, olhando-se da perspectiva institucional (NORTH, 2007), esse esforço dependeria exclusivamente das leis, das instituições e dos gestores públicos. Todavia, pela luz da teoria do Capital Social de Putnam (2000), seríamos levados a observar que os aspectos socioculturais de uma determinada região têm influência direta sob as instituições, no nosso caso, na qualidade do desempenho e na participação nas políticas públicas. Particularmente nos interessa, por razões geográficas e culturais, estudar as cidades de Novo Hamburgo e Caxias do Sul, no Estado do Rio Grande do Sul, que sofreram, predominantemente, a influência da imigração alemã e italiana a partir do século XIX, respectivamente.

Nesta direção, de forma original, este trabalho busca à luz da teoria do capital social, analisar comparativamente a qualidade da participação dos usuários do Sistema Único de Assistência Social (SUAS) nas cidades de Caxias do Sul e Novo Hamburgo, no Rio Grande do Sul. Nessa perspectiva, a nossa hipótese de trabalho sugere, a partir da relação definida por Putnam (2000), a qual o acúmulo de capital social existente numa determinada região, ou seja, suas relações de confiança interpessoal, de participação política e a cultura cívica estão positivamente correlacionadas com o fortalecimento e a ampliação da participação nas políticas públicas. A metodologia utiliza resultados de pesquisa quantitativa, tipo Survey, a qual se constituem em uma investigação que colhe dados de amostra representativa de uma população específica, que são descritos e analiticamente explicados. Pretende-se que os resultados sejam generalizáveis ao universo desta população, evitando-se realizar o censo, ou seja, ouvir todos os indivíduos, o que é geralmente, impossível, por questão de custo e de tempo (Babbie, 2005). Desta forma, em 2016 foram realizadas duas baterias de testes, onde, na cidade de Caxias do Sul dentro de um universo $(\mathrm{N})$ de 30.500 usuários, a mostra (n) foi constituída de 211 questionários; Já na cidade de Novo Hamburgo, tendo como universo (N) 24.690 usuários, obteve-se como amostra (n) 171 questionários, totalizando 382, com erro amostral de $5 \%$ e coeficiente de confiança de $95 \%^{3}$. Os questionários foram aplicados diretamente aos usuários do SUAS, maiores de 18 anos e referenciados aos aparelhos públicos Centro de Referência de Assistência Social (CRAS) e Centro de Referência Especializado de Assistência Social (CREAS), levando em conta as normas aplicáveis a pesquisas em Ciências Sociais e Humanas, segundo a res. 510/16, do Ministério da Saúde.

Somado a pesquisa Survey, nos propomos a construção do Índice de Capital Social (ICS), sendo os indicadores que compõe este índice, adaptados às condições e características do local analisado ${ }^{4}$. Neste sentido, foram estabelecidas algumas

\footnotetext{
${ }^{3}$ Foi utilizado a metodologia de amostra probabilística e seu desdobramento foi constituído pela técnica de amostra por grupos (ALMEIDA NETO, 2008). ${ }^{3} \mathrm{O}$ cálculo amostral foi composto pela seguinte fórmula: $n=Z 2 \quad p(1-p) N /(N-!) e 2+Z 2 p(1-p)$ ( $n$ : amostra calculada , N: população, Z: váriável normal, p: real probabilidade do evento, e: erro amostral) (Barbetta, 2010).

${ }^{4} \mathrm{O}$ Índice de Capital Social (ICS) foi construído de forma idêntica para as duas regiões a partir da seleção de nove questões relativas ao capital social, sendo elas: (1) "Em termos gerais, o senhor diria que se pode confiar nas pessoas ou não se pode confiar nas pessoas?" Sim (peso 2), Não (peso o); (2) "Gostaria de saber se o senhor confia muito (peso 2), pouco (peso 1) ou não confia (peso o) na: igreja, família, vizinhos, associações comunitárias, sindicatos"; (3) "O senhor costuma participar de: partidos políticos, reuniões políticos, comícios, associações comunitárias, associações religiosas,
} 
afirmações com relação a hábitos e costumes da população, onde para cada afirmação, foi atribuído valor 2; para cada negação, valor o; e, para cada possibilidade remota (as vezes, pouco), valor 1. Desta forma, o índice de capital social é formado pela agregação das duas primeiras respostas (indicando as respostas positivas) e pela agregação da última resposta (indicando a resposta negativa). Desta forma, para verificarmos o acúmulo de capital social, inspirados em Khan e Silva (2002), estabelecemos o seguinte critério: Baixo nível de capital social $0<$ ICS $\leq 0,5$; Médio nível de capital social - 0,5 < ICS $\leq 0,8$; Alto nível de capital social $-0,8<$ ICS $\leq 1$.

Para a análise dos dados, somado a metodologia de análise comparada entre as cidades estudadas, utilizaremo-nos do Teste Qui-quadrado $\left(\mathrm{X}^{2}\right)$, o qual permite testar a significância (grau de associação) entre duas variáveis qualitativas (MEIRELLES, 2014). Desta forma, quando o valor do teste ficar entre 0\% (Sig = 0,00) e 0,5\% (Sig = 0,05), devemos aceitar a hipótese alternativa, qual seja, capital social está associado com a participação no SUAS e rejeitar a hipótese nula, qual seja, capital social não está associado com a participação no SUAS, indicando que as variáveis capital social e participação no SUAS estão associadas estatisticamente.

Assim, num primeiro momento, buscaremos apresentar nossa compreensão sobre as políticas públicas, sugerindo a relevância da cultura política como elemento de sustentação da democracia, no contexto brasileiro; Em seguida, lançaremos o debate sobre capital social como um vetor de desenvolvimento, em especial, para o fortalecimento da participação nas políticas públicas. Por fim, demonstraremos, a partir de uma perspectiva de Putnam, a associação positiva entre capital social e participação, nas cidades em tela

\section{A contribuição do capital social para as políticas públicas}

Ao analisarmos o contexto brasileiro, os estudos sobre as políticas públicas têm início no século XX, muito embora nos anos 1980 haja uma retomada das análises sobre políticas de gestão dos governos, de políticas públicas e de políticas em geral. Segundo Miceli (1999), a tradição de análise das políticas públicas, segue a escola anglo-saxônica, mais especificamente a norte-americana, pelos pressupostos

associações sindicais, conselhos populares, ONGs, orçamento participativo, abaixo assinados, manifestações ou protestos, greves, ocupação de terrenos ou prédios públicos, outros" Sim (peso 2), Não (peso o); (4) "Nos últimos anos, o senhor tentou resolver algum problema local do bairro/comunidade junto com outras pessoas?" Sim (peso 2), Não (peso o); (5) "Dentre os grupos que eu vou mencionar, quais deles existem no seu bairro: grupo político, grupo ou associação cultural, grupo educacional, grupo esportivo, grupo de jovens, ONG ou grupo cívico, grupo baseado na comunidade étnica, grupos de mulheres, outro" Sim (peso 2), Não (peso o); (6) "Atualmente o senhor participa de algum grupo ou organização?" Sim (peso 2), Não (peso o); (7) "Se precisasse viajar por um ou dois dias, o senhor poderia contar com vizinhos para cuidar da sua casa e/ou filhos?" Sim (peso 2), Provavelmente (peso 1), Não (peso o); (8) “Em uma situação de emergência como a doença de um familiar ou perda de emprego, o senhor receberia ajuda:" familiares (peso o), vizinhos (peso 2), colegas de trabalho (peso 2); (9) "Se um projeto da comunidade não lhe beneficia diretamente, mas pode beneficiar outras pessoas do seu bairro, o senhor contribui para este projeto?" Sim (peso 2), Não (peso o). Para a construção do referido índice, contamos com a assessoria estatística do Centro de Pesquisa e Planejamento (CPP) da Universidade Feevale. 

pública.

do 'antiestatismo liberal' e pelos estudos da cultura política, ensejando os estudos sobre "o Estado em ação".

O significativo crescimento dos estudos sobre políticas públicas, a partir do final da década de 1980, é fortemente marcado pelo sentimento de otimismo relacionado com a redemocratização do Brasil (MICELI, 1999). A crença na institucionalização da democracia alimentou os anseios de vencer o legado histórico de desigualdade e pobreza no Brasil. Mais a diante, frustrada esta crença, coabitou um sentimento de desencantamento pelo Estado, voltando-se assim a estudos sobre os desafios da ação e da gestão pública. E, por último, já na década de 1990, as análises são motivadas pelos processos de reforma neoliberal do Estado, tomando como objeto a forma de ação dos governos na economia e na sociedade. Nesse momento, os trabalhos, influenciados pelas teorias do capital social, sociedade civil e cultura política passaram a analisar as bases de sustentação social do regime democrático e das políticas públicas.

Os principais estudos, primeiramente versavam sobre o autoritarismo, clientelismo, corporativismo, planejamento econômico, políticas industriais e desenvolvimento regional. Após a transição democrática e, consequentemente, pela incorporação de princípios da participação no Estado, estes estudos passaram a se relacionar aos tipos de clientela das políticas, impacto das políticas sobre a estrutura social, exclusão social e cidadania. Atrelado a isto, volta-se para o problema de gestão governamental, assumindo um caráter crítico, maximalista e dissociado da prática de governo (MICELI, 1999). Desta forma, segundo Lotta (2019), os estudos sobre a implementação das políticas públicas são os mais recentes, tendo em vista que os primeiros estudos estavam preocupados com os processos decisórios, a relação entre as políticas e o funcionamento da democracia. Assim, conforme recente mapeamento dos modelos de análise das políticas públicas de Dye (2014), tem se voltado para as teorias do institucionalismo, da política como atividade política, dos grupos, da elite, do racionalismo, do incrementalismo, entre outros.

Sobre os tipos de políticas públicas, a literatura especializada tem cotejado diferentes abordagens, como a atenção as dimensões técnica e política de Bozeman e Pandey (2004); A distinção entre as políticas reais, simbólicas e pseudopolíticas de Gustafsson (1983); As políticas do tipo clientelista, de grupo de interesses, empreendedoras e majoritárias de Wilson (1987); As abordagens de políticas regulatórias, distributivas, constitutivas e redistributivas de Lowi (1964); A operacionalização de políticas públicas pelos modelos: principal-agente, rede de políticas públicas, elitista e pluralista de Secchi (2014), são alguns exemplos.

Neste sentido, as políticas públicas têm se tornado um campo do conhecimento em grande expansão na atualidade, servindo, contudo, para múltiplas interpretações e tornando difuso o seu conceito. Para tanto, busca-se diferenciar polity - relacionado às instituições do Estado; Politics - considerado o processo político, "o jogo político"; e policy, diz respeito às políticas públicas, constituindo respostas do Estado (NOGUEIRA, 2002). Segundo este último entendimento, o qual nos filiamos, na perspectiva, "política pública é uma diretriz elaborada para enfrentar um problema público, constituindo-se de uma intencionalidade pública e a resposta a um problema público" (SECCHI, 2014, p. 2). Complementa Lahera (2012), que políticas públicas indicam a ação de uma 
autoridade pública ao colocar em marcha uma política ou programa. Para este trabalho, respaldados por Souza (2006, p.26), entendemos política pública como

O campo do conhecimento que busca, ao mesmo tempo, "colocar o
governo em ação" e/ou analisar essa ação (variável independente) e,
quando necessário, propor mudanças no rumo ou curso dessas ações
(variável dependente). Em outras palavras, o processo de formulação de
política pública é aquele através do qual os governos traduzem seus
propósitos em programas e ações, que produzirão resultados ou as
mudanças desejadas no mundo real.

Neste sentido, observa-se uma tensão embrionária na formulação das políticas públicas, expressando-se em uma assimetria, onde, a formulação das políticas públicas tem se dado outorgada pelo Estado, sem a participação da sociedade. Contudo, constata-se que a implementação de tais políticas, dependerá, a grosso modo, da iniciativa da sociedade. Essa assimetria, deflagra a formulação das políticas públicas em disputa, pois, num primeiro momento, coloca em evidência a abordagem estatista, considerando que políticas públicas são exclusivamente emanadas pelo Estado. Num segundo momento, uma abordagem multicênica considera que outros grupos sociais e políticos também contribuem para a formulação de políticas. Neste contexto de diferentes abordagens, entre as políticas públicas no Brasil, a Política Nacional de Assistência Social (PNAS), vem sendo operacionalizada por meio do Sistema Único de Assistência Social (SUAS) (Brasil, 2005, p.33), onde as "ações são organizadas em sistema descentralizado e participativo, constituído pelas entidades e organizações de assistência social, articulando meios, esforços e recursos, e por um conjunto de instâncias deliberativas", composto por dois níveis de proteção: básica e especial.

Considerando a inclinação da experiência brasileira para estudos de políticas públicas voltados para a ação do Estado, numa perspectiva institucionalista, colocase a problemática: as políticas públicas dependeriam exclusivamente das instituições políticas para promover um bom desempenho institucional? Ou as políticas públicas teriam que contar com elementos da cultura política e com recursos sociais como vetores para este desenvolvimento? Considerando a atual crise das instituições políticas e o cenário de tensões entre Estado e a sociedade, a bibliografia, grosso modo, tem se bifurcado entre duas grandes tradições de estudos, o institucionalismo e o culturalismo (NORTH, 2007; PUTNAM, 2000), para explicar o desempenho institucional dos governos.

Neste sentido, mesmo considerando a realização de eleições limpas, a eficiência governamental e o consenso entre algumas das principais tarefas da democracia, a sua estabilidade necessita de uma infraestrutura social adequada (FERRAZ, 1971; 2016). O aspecto da infraestrutura social envolve a atenção também de Baquero (2016) atualidade, na medida em que o mesmo utiliza o conceito de "democracia inercial" para sugerir que no Brasil, por meio das teorias de escolhas racional e institucional, afirmava-se que as instituições formais, aos poucos, seriam capazes de solucionar (automaticamente) os problemas sociais e políticos. Contudo, essa perspectiva não tem se comprovado, pois, quando crises econômicas se instauram, elas produzem crises de credibilidade nas instituições, colocando em xeque a própria legitimidade de um governo democraticamente eleito (BAQUERO, 2016). O fato fica evidente, na atualidade, conforme última pesquisa de opinião 

pública.

pública sobre a avaliação do Governo Federal, onde 32\% da população considera a sua gestão ótima/boa, $33 \%$ regular, $30 \%$ péssima ou ruim e $4 \%$ não sabe/não respondeu ${ }^{5}$, sendo a pior avaliação para um presidente da República no início de primeiro mandato desde 1990 (DATA FOLHA, 2019).

Colocam-se em cheque duas perspectivas: as instituições como variáveis independente e dependente. Na primeira vertente teórica, a cultura política exercida pelos cidadãos e governos, bem como a qualidade do tecido social, não se constitui elemento central para se alcançar o bom desempenho institucional, atribuindo um peso determinante as instituições, às leis e aos recursos públicos (TABELINI, 2005; OLSON, 1999). Na segunda vertente, as instituições como variável dependente, segundo Wittmann e Ramos (2004), atentam-se para os pré-requisitos sócio-históricos e culturais necessários para o desenvolvimento social, entre eles: a integração social, os indicadores empíricos, sociais e econômicos e a geração e distribuição de capital social, estes como elementos centrais para o bom desempenho institucional.

Quando analisamos as políticas na atualidade a partir de um sinergismo entre as variáveis dependentes e independentes, em especial no contexto do Rio Grande do Sul, constata-se, entre outros, o grande desafio do aprofundamento da democracia, que não é recente para ação dos governos, os quais necessitam responder às demandas sociais e articular os recursos escassos do Estado. Diante deste panorama tem se voltado para os estudos do capital social e da cultura política como elementos imprescindíveis para sustentação das instituições democráticas (PUTNAM, 2000; ARROW, 1974; DOWBOR, 2003; GIDDENS, 2007; TABELLINI, 2005; BAQUERO, 2007; SANTOS, 2013, entre outros). Nessa direção, sugere-se que a cultura política, os valores cívicos e a confiança são aspectos que auxiliam as instituições democráticas e os governos em geral no seu papel de promover o desenvolvimento econômico (TABELINI, 2005), sendo "esta uma questão que nenhuma "engenharia institucional" pode resolver" (BAQUERO, 2003, p.17). Neste caso, as políticas públicas para constituírem-se fortes e participativas deveria combinar os aspectos formais (institucionais) e informais (socioculturais) da sociedade.

Nesta direção, o capital social, como um conceito polissêmico (sociológico, econômico, político, cultural), pode ser uma proposta estimulante ${ }^{6}$. Diante de várias interpretações do conceito de capital social, a perspectiva histórica e econômica de Wittman, Ramos (2004, p.42) esclarece que "a base do capital social é a constituição de um sólido sistema de intercâmbio de signos e informações [...] Mais exatamente a transformação do credere (confiança) em crédito". No sentido empregado pelos autores, a contribuição do capital social foi fundamental para o desenvolvimento do Estado do Rio Grande do Sul, no período colonial. Desta forma, a solução encontrada para a carência de capital financeiro fora o desenvolvimento precoce de um sólido capital social, constituído de uma base de crédito fiduciário,

\footnotetext{
${ }^{5}$ Fernando Collor (então no PRN) tinha 19\% de reprovação, contra 16\% de FHC (PSDB), 10\% de Lula (PT) e 7\% de Dilma (PT). A pesquisa Data Folha ouviu 2.086 pessoas com mais de 16 anos, em 130 municípios, nos dias 2 e 3 de abril de 2019. A margem de erro é de dois pontos percentuais, para mais ou para menos.

${ }^{6}$ Contudo, as associações e grupos podem ser tão importantes quando prejudicais. Na verdade, o Estado tem um papel elementar em mobilizar recursos para dotar os cidadãos de cidadania e liberdade, bem como desencadear processos locais de participação (SZRETER, 1999).
} 
calcado na homogeneidade econômica (todos são proprietário) e cultural (como imigrantes, comungam da mesma origem).

Em outro ponto de vista, Szreter (1999) irá se apoiar nos pressupostos das relações de confiança e na qualidade das relações entre grupos sociais como bases constitutivas de capital social, pois, o "capital social decorre de relações mutuamente respeitosas e fidedignas que permitem a um grupo seguir suas metas comuns com maior eficiência do que seria possível em outras circunstâncias" ( $p$. 406). Para Fukuyama (1996, p.41), a compreensão da vida econômica está intrinsecamente ligado à vida social, onde o "capital social decorre da prevalência de confiança numa sociedade [...] Difere de outras formas de capital humano na medida em que geralmente criado ou transmitido por mecanismos como a religião, tradição ou hábito histórico".

Contudo, nosso entendimento sobre capital social recai sobre a teoria de Putnam (2000), onde as instituições são importantes marcos político-legais que tencionam mudanças na sociedade, mas essas são moldadas pelo contexto sociocultural onde estão inseridas. Nessa perspectiva de análise, investe-se nos aspectos socioculturais como dispositivos de propensão e acumulação de capital social, influenciando positivamente no desempenho institucional, e não o contrário. Desta forma, a confiança interpessoal de uma sociedade, o seu engajamento cívico e a sua participação política estão na base do sucesso de instituições democráticas estáveis e eficazes. Nesse sentido, Putnam (2000), ao pesquisar a realidade italiana por mais de 20 anos, tem como pressupostos teóricos buscar compreender quais são as condições necessárias para a criação instituições fortes, eficazes e responsáveis. Assumindo um viés culturalista, o autor vai atrelar características do contexto sociocultural para explicar porque o norte da Itália teve melhor desempenho institucional e capacidade de governança, em relação ao sul da Itália. Dessa forma, capital social, para Putnam (2000, p.137), diz respeito ao

Conjunto de recursos sociais possuído por um grupo, através de redes de trabalho com as quais se constitui uma comunidade cívica, sentimentos de solidariedade e igualdade com os demais membros da comunidade, normas de cooperação, reciprocidade, confiança e atitudes positivas, reveladas através da confiança no outro, no governo e no funcionamento das instituições.

Nesta direção, Putnam (2000) conclui a existência de uma significativa associação entre engajamento cívico, redes de confiança interpessoal e o desempenho das instituições políticas. Para além, recentes pesquisas indicam que o capital social está associado com o fortalecimento e o empoderamento da democracia (BAQUERO, 2013), com a ampliação da confiança nas instituições do Estado (GIDDENS, 1999) e para o melhor desempenho das políticas públicas (BAQUERO, 2013; SANTOS, 2013). Neste último aspecto, Santos (2013), ao estudar a relação entre democracia e capital social no Rio Grande do Sul, sugere que futuras pesquisas, oportunamente, poderiam explorar bem mais a relação entre capital social e participação societal. 

pública.

\section{0 tema da participação nas políticas públicas}

Os temas de participação e descentralização estão entre os maiores desafios postos as políticas públicas pós Constituinte, bem como são uma das temáticas que mais se têm produzido no Brasil, sobretudo nas últimas duas décadas.

Historicamente, em Rousseau (1968), a participação é importante para a proteção dos interesses privados dos cidadãos e para assegurar um bom governo. Para Mill (2001), o desenvolvimento de uma comunidade está atrelado à oportunidade dos indivíduos de expressarem-se e envolveram-se em um 'espírito público'. A teoria de Cole (1920) enfatiza que a participação em nível local e em associações seria capaz de lançar elementos para o aprendizado do indivíduo sobre a democracia. Em Tocqueville (1998), participar tem a função de 'educar' a democracia mediante a formação de homens independentes e capazes de autogoverno. Para Bobbio et al (1998), numa perspectiva política, participação se trata de toda a ação pública que interfere na organização e/ou distribuição dos recursos do Estado. Na abordagem de Gohn (2011), a participação refere-se a processos de lutas sociais voltadas para a transformação de condições existentes na realidade social, de carências econômicas e/ou opressão sócio-política.

Para os limites deste trabalho, nos filiamos a perspectiva de Bordenave (1983), em que participação é analisada como um processo onde as diversas camadas sociais têm parte na produção, na gestão e no usufruto dos bens de uma sociedade historicamente determinada. Esta participação envolve deste um nível inexpressivo de participação, indo até um nível mais sofisticado de participação, desta forma: em nível de informação, a população é apenas informada das decisões já tomadas pelos governantes; Em nível de consulta, a população é consultada em certas ocasiões, embora a decisão final pertença aos governantes; Em nível de elaboração, a população é convidada a expressar críticas ou sugestões, sendo os governantes obrigados a justificarem as suas escolhas; Em nível de delegação, a população escolhe os objetivos e os meios para resolver os problemas (BORDENAVE, 1983).

Neste contexto, após a promulgação da Constituição Federal, a participação passa a ser um paradigma das políticas públicas em geral, propondo uma nova relação entre Estado e sociedade, por meio da participação popular na gestão e avaliação das políticas públicas. Na área da saúde, a Lei 8.142/90, no seu artigo $1^{\circ}$, § $1^{\circ}$, dispõe sobre a participação da comunidade na gestão do Sistema Único de Saúde (SUS); Na área da educação, a Lei 10.576/95, no seu artigo $1^{\circ}, \S 3^{\text {a }}$, institui a participação dos segmentos da comunidade escolar nos processos decisórios em órgãos colegiados, assim como em outras áreas. $\mathrm{Na}$ área de assistência social, por meio da Lei Orgânica de Assistência Social (LOAS), nº 8.742/93, no seu art. $5^{\circ}$, buscase assegurar a participação da população por meio de organizações representativas na formulação das políticas e no controle das ações em todos os níveis federativos (municipal, estadual e federal); Mais recentemente, o decreto $\underline{n}^{\circ} 8.243 / 14$, institui a Política Nacional de Participação Popular, com vistas a fortalecer e articular os mecanismos e as instâncias democráticas de diálogo e a atuação conjunta entre a administração pública federal e a sociedade civil, conforme o seu artigo $1^{\circ}$.

Contudo, pelo prisma dos mecanismos participativos expressos na Constituição Federal (Brasil, 2015), no seu artigo 14, como: plebiscitos (inciso I), 
referendos (inciso II) e projetos de lei por iniciativa popular (inciso III), a condição da sociedade se expressar, permanece insipiente. Para exemplificar, muito embora a promulgação dos dispositivos legais citados, passadas quase três décadas, temos apenas quatro (4) projetos de iniciativa popular, sancionados pelo Senado Federal, sendo eles: Lei $n^{\circ}$ 8.930/94, de Crimes Hediondos; Lei $n^{\circ}$ 9.840/99, contra a Corrupção Eleitoral; Lei Completar $n^{\circ} 11.124 / 05$, que dispõe sobre o Sistema Nacional de Habitação de Interesse Social (SNHIS) e Lei Complementar $n^{\circ} 135 / 10$, da Ficha Limpa (MARQUES; SANTOS; KUHN JUNIOR, 2016). Desta forma, somado a perspectiva institucional, vamos discutir, na sequência deste trabalho, o alcance do capital social para a promoção da participação nas políticas públicas.

\section{Capital social e participação nas cidades de Caxias do Sul e Novo Hamburgo no RS}

No Brasil, em especial no Rio Grande do Sul, pesquisas vêm replicando o arcabouço teórico de Putnam (2000), buscando explicar significativos contrates regionais entre o "Norte gaúcho", com pouca escravidão e a presença do minifúndio; e o "Sul gaúcho", com a presença marcante do latifúndio e do trabalho escravo (BANDERA, 2003; SANTOS, 2013, BAQUERO, 2015, PASE, 2016). Dessa forma, pesquisas têm sugerido para um acúmulo maior de capital social no Norte, em especial na cidade de Caxias do Sul (BANDERA, 2003; BASTOS, 2009) e no Nordeste (SANTOS, 2013), muito embora verifica-se também a presença positiva do capital social no município de Novo Hamburgo (SANTOS, 2013; 2016), apontando assim, para a constituição de uma comunidade cívica, na qual poderia haver um melhor funcionamento das instituições e das políticas públicas. Este acúmulo de capital social, para os limites deste trabalho, não guarda uma relação direta com as questões culturais e/ou étnicas nessas cidades, como resultado daquilo que tem sido chamado pela literatura como o "mito da italianidade" em Caxias do Sul (SANTOS; ZANINI, 2009; HERÉDIA, 2005; CARAGNATO, 2010), e do "espírito obreiro do alemão" em Novo Hamburgo (SCHÜTZ, 1976), numa perspectiva antropológica. Contudo, nosso trabalho, está voltado para o tipo de organização social erguida ao longo da formação destas cidades, voltando-se nosso olhar para os aspectos de participação em grupos e associações, a confiança nas pessoas, o envolvimento cívico, entre outros, assim, numa perspectiva sociológica.

A cidade de Novo Hamburgo, marcada pela colonização alemã, no início do século XIX se constitui em um distrito da cidade de São Leopoldo, sendo emancipada em 5 de abril de 1927. Está localizada a 40 quilômetros da capital do Estado, Porto Alegre, integrando a região do Vale do Rio dos Sinos. A cidade é reconhecida como a Capital Nacional do Calçado, com Produto Interno Bruto (PIB) de R\$ 8.122.335,91 (mil) e Índice de Desenvolvimento Humano Municipal (IDHM) de 0,747 e possui uma população de cerca de 238.940 mil habitantes (IBGE, 2012).

A cidade de Caxias do Sul é marcada pela colonização italiana, no início do século XIX, tendo início no lugarejo de Colônia de Caxias, sendo elevada a cidade em $1^{\circ}$ de julho de 1910. Está localizada a 128 quilômetros da capital do Estado do Rio Grande do Sul, integrando a região da Serra. A cidade integra, junto a outros municípios, uma região reconhecida pela produção de vinhos e derivados, com PIB de $R \$$ R\$ 20.637.191,76 (mil) e IDHM de 0,782 e tem uma população de 435.564 mil habitantes (IBGE, 2012). 

pública.

Neste sentido, somado aos aspectos da formação sociocultural e o acúmulo do capital social, para a escolha dos municípios, foram levados em consideração também critérios institucionais, tais como: ambos os municípios são considerados de grande porte ${ }^{7}$; ambos têm o nível de gestão plena do $\operatorname{SUAS}^{8}$ e, ambos dispõem da mesma quantidade de aparelhos públicos, sendo 6 (seis) CRAS e 2 (dois) CREAS. Desta forma, coloca-se a problemática: considerando, na sua maioria, as semelhanças institucionais dos municípios, seria o capital social o vetor relacionado com a qualidade da participação nas políticas públicas?

Inicialmente, em relação à confiança nas pessoas, numa perspectiva comparada, constata-se em ambos os municípios um baixo percentual de confiança, conforme tabela 1. Abaixo.

Tabela 1. Confiança nas pessoas nas cidades de Caxias do Sul e Novo Hamburgo (\%)

\begin{tabular}{|lcc|}
\hline & Caxias & Novo \\
Entrevistados que confiam nas pessoas & do Sul & Hamburgo \\
Entrevistados que não confiam nas pessoas & 31 & 24 \\
Total: & 69 & 76 \\
\hline
\end{tabular}

Nota. Total: Caxias do Sul N=211 - Novo Hamburgo N=171

Fonte: próprios autores

Verifica-se que em Caxias do Sul um percentual maior de entrevistados que afirmam que se pode confiar nas pessoas (31\%), em relação a Novo Hamburgo (24\%). Podemos sugerir que este panorama, esteja colado ao cenário atual de crise econômica e política do País, de queda na confiança nos governos, respectivamente, nas instituições e nas políticas públicas e o descontentamento com o contexto de corrupção, apontado pela população.

Em relação ao aspecto da confiança nas instituições, a família é que alcança os escores mais altos e, praticamente, mantém-se idêntica nas duas cidades, sendo 92\% em Caxias do Sul e $91 \%$ em Novo Hamburgo. O aspecto pode ser melhor contemplado, conforme a tabela 2, abaixo:

Tabela 2. Confiança nas instituições nas cidades de Caxias do Sul e Novo Hamburgo (\%)

\begin{tabular}{|c|c|c|}
\hline & $\begin{array}{l}\text { Caxias } \\
\text { do Sul }\end{array}$ & $\begin{array}{c}\text { Novo } \\
\text { Hamburgo }\end{array}$ \\
\hline Entrevistados que confiam na família & 92 & 91 \\
\hline Entrevistados que confiam nos vizinhos & 65 & 73 \\
\hline Entrevistados que confiam nas igrejas & 82 & 85 \\
\hline Entrevistados que confiam nas associações de moradores & 70 & 65 \\
\hline Entrevistados que confiam nos sindicatos & 73 & 66 \\
\hline
\end{tabular}

Nota. Total: Caxias do Sul N=211 - Novo Hamburgo N=171

Fonte: próprios autores

\footnotetext{
7 São aqueles cuja população é de 101.000 até 900.000 habitantes (BRASIL, 2004).

${ }^{8}$ Gestão em níveis de proteção social básica e especial (BRASIL, 2004).
} 
Como podemos observar na tabela 2, em ambas as cidades, a família é a instituição em que mais se confia. Também, na cidade de Caxias do Sul, os usuários confiam mais nas instituições denominadas 'intermediárias', aquelas que não pertencem ao Estado ou à família, sendo os sindicatos (73\%) e as associações de moradores (70\%). Em Novo Hamburgo, as igrejas contam com uma confiança um pouco maior ( $85 \%$ ) do que em Caxias do Sul (82\%). Este cenário aponta para um importante elemento de capital social encontrado com um pouco mais de abundância em Caxias do Sul, qual seja, a confiança para além das relações de parentesco e daquelas em o Estado foi sempre o promotor.

Em relação à participação da população em instituições intermediárias, embora este aspecto alcance escores relativamente baixos, em ambos os municípios, em Caxias do Sul, observa-se um ambiente mais virtuoso, como segue abaixo a tabela 3 .

Tabela 3. Participação em instituições e associações nas cidades de Caxias do Sul e Novo Hamburgo (\%)

\begin{tabular}{|lcc|}
\hline Entrevistados que participam de partidos políticos & $\begin{array}{c}\text { Caxias } \\
\text { do Sul }\end{array}$ & $\begin{array}{c}\text { Novo } \\
\text { Hamburgo }\end{array}$ \\
Entrevistados que participam de reuniões políticas & 5 & 5 \\
Entrevistados que participam de comícios & 4 & 7 \\
Entrevistados que participam de associação de moradores & 8 & 13 \\
Entrevistados que participam de associações religiosas & 19 & 14 \\
Entrevistados que participam de associações sindicais & 6 & 25 \\
Entrevistados que participam de ONG & 7 & 5 \\
Entrevistados que participam de Orçamento participativo & 13 & 6 \\
Entrevistados que participam de abaixo assinado & 14 & 13 \\
Entrevistados que participam de manifestações ou protestos & 7 & 7 \\
Entrevistados que participam de greves & 5 & 3 \\
Entrevistados que participam de ocupação de terreno & 6 & 5 \\
Entrevistados que participam de outros espaços & 5 & 4 \\
\hline
\end{tabular}

Nota. Total: Caxias do Sul N=211 - Novo Hamburgo N=171

Fonte: próprios autores

Observando-se a tabela 3, constata-se que das 13 associações e instituições as quais os entrevistados disseram participar, em 8 delas Caxias do Sul ficou à frente, ao passo que Novo Hamburgo ficou à frente em apenas 2. A participação em associações de moradores, orçamento participativo e em greves é bem mais expressiva na sociedade caxiense, tendo uma participação de 19\%, 13\% e 5\%, respectivamente, contra $14 \%, 6 \%$ e $3 \%$ em Novo Hamburgo. Constata-se uma igual participação em partidos políticos (5\%) e em ONG's (7\%). Em Novo Hamburgo, temse melhores índices apenas em relação à participação em reuniões políticas (7\%) e em comícios (13\%).

Seguido a nossa análise, sobre o aspecto do engajamento cívico, conforme a tabela 4, na cidade de Caxias do Sul encontramos um percentual maior de entrevistados que costumam resolver os problemas do bairro junto com outras pessoas (38\%), que participam de algum grupo no bairro (26\%) e que participaram de algum projeto, mesmo sem nenhum benefício próprio (90\%). 
Tabela 4. Engajamento cívico nas cidades de Caxias do Sul e Novo Hamburgo (\%)

\begin{tabular}{|lcc|}
\hline & $\begin{array}{c}\text { Caxias } \\
\text { do Sul }\end{array}$ & $\begin{array}{c}\text { Novo } \\
\text { Hamburgo }\end{array}$ \\
Resolução de problemas do bairro com outras pessoas & 38 & 33 \\
Participação em algum grupo ou organização no bairro & 26 & 24 \\
Participação em projeto sem nenhum benefício próprio & 90 & 83 \\
\hline
\end{tabular}

Nota. Total: Caxias do Sul N=211 - Novo Hamburgo N=171

Fonte: próprios autores

Sobre o aspecto dos entrevistados que "costumam resolver os problemas do bairro junto com outras pessoas”, segundo Putnam (2000), a experiência italiana mostrou que as práticas de clientelismo foram paulatinamente enfraquecidas, em detrimento de práticas de mobilização social e de participação na gestão das instituições do Estado. Sobre a participação voluntária em algum projeto no bairro, seguindo respaldados em Putnam (2000, p.113), "regiões onde a comunidade não costuma participar dos referendos, não lê jornal, nem participa de associações cívicas, são as mesmas descritas pelos líderes comunitários como "política regional clientelista", não "programática e envolvida por uma cultura de desconfiança”. Já o aspecto de envolvimento em algum grupo ou organização social, Stassen (2011) enfatiza que os mecanismos informais de integração social nas redes societárias que criam as identidades podem ser tão importantes quanto as chamadas políticas sociais de empregos, por exemplo. Neste sentido, em relação ao engajamento cívico, conforme a tabela 4, a cidade de Caxias do Sul parece contar um estoque um pouco maior deste importante elemento do capital social.

Em relação ao Índice de Capital Social (ICS) nas cidades estudadas, consideramos que é possível medir o seu estoque a partir de informações sobre grupos e integrantes de grupos, além da participação política e da confiança interpessoal (RIBEIRO ET AL., 2012; SANTOS, 2013; INGLEHART, 2001), conforme tabela 5, abaixo.

Tabela 5. Índice de Capital Social (ICS) das cidades de Caxias do Sul e Novo Hamburgo

\begin{tabular}{|lcc|}
\hline Indicador & Caxias do Sul & $\begin{array}{c}\text { Novo } \\
\text { Hamburgo } \\
\text { Confiança nas pessoas }\end{array}$ \\
Confiança nas instituições & Valor & 0,246 \\
Participação em grupos e associações & 0,313 & 0,388 \\
Resolver problemas com outras pessoas & 0,380 & 0,165 \\
Conhecimento sobre grupos no bairro & 0,190 & 0,327 \\
Envolvimento em grupo ou organização & 0,379 & 0,286 \\
Confiança nos vizinhos & 0,335 & 0,240 \\
Redes de amizade & 0,261 & 0,280 \\
Engajamento cívico & 0,294 & 0,250 \\
Total: & 0,250 & 0,842 \\
\hline
\end{tabular}

Nota. Total: Caxias do Sul N=211 - Novo Hamburgo N=171

Fonte: próprios autores 
De uma maneira geral, podemos constatar que o município de Caxias do Sul obteve escores um pouco melhores do que o município de Novo Hamburgo, sendo os mais expressivos os indicadores de "confiança nas pessoas" $(0,313)$ e o "conhecimento sobre grupos no bairro" (0,335). O indicador "redes de amizade" ficou idêntico nos dois municípios (0,250). Os demais indicadores, participação em grupos e associações, resolver problemas com outras pessoas, envolvimento em grupo ou organização e confiança nos vizinhos, apresentam-se com percentuais bem próximos nas duas cidades, com um escore um pouco maior em Caxias do Sul.

Constata-se que o indicador "engajamento cívico" foi o mais importante (de maior peso) na determinação do Índice de Capital Social em ambas as cidades. De forma particular, na cidade de Novo Hamburgo, a participação em grupos e associações, pela população, mostra-se bastante inexpressiva $(0,165)$. Neste sentido, dentre as cidades analisadas, Caxias do Sul é que apresentou índice um pouco maior de capital social $(0,366)$, em relação à cidade de Novo Hamburgo $(0,336)$. De uma maneira geral, os valores encontrados apontam para um baixo nível capital social nas duas regiões, sendo o de Novo Hamburgo mais baixo ainda. Essa tendência de existência de diferenças entre as regiões, encontra-se relacionada na literatura sobre o capital social no Rio Grande do Sul (BANDEIRA, 2003; MONASTERIO, 2013, PASE, 2016, entre outros). Em especial os estudos de Santos (2013) sugerem um índice de capital social de 0,292 para a região do Vale dos Sinos, onde se localiza a cidade de Novo Hamburgo e, 0,426 para a região Nordeste, mais próximo, geograficamente, da cidade de Caxias do Sul, portanto, destacado diferenças entre as regiões.

\subsection{Políticas públicas e participação no RS: capital social é a resposta?}

Primeiramente, como no nível mais elementar de participação, o de informação (BORDENAVE, 1983), podemos observar na tabela 6, que a maioria da população do SUAS fala pouco durante uma reunião.

Tabela 6. Participação em nível de informação nas cidades de Caxias do Sul e Novo Hamburgo (\%)

\begin{tabular}{|lcc|}
\hline Durante uma reunião, o Sr. & Caxias do & Novo \\
costuma? & Sul & Hamburgo \\
Falar muito & 17 & 19 \\
Falar pouco & 60 & 67 \\
Não fala & 23 & 24 \\
Total & 100 & 100 \\
\hline
\end{tabular}

Nota. Total: Caxias do Sul N=211 - Novo Hamburgo N=171

Fonte: próprios autores

Conforme a tabela a cima, a mesma aponta que 60\% da população de Caxias do Sul e $67 \%$ da população de Novo Hamburgo, fala pouco. Também, os índices da população que não fala durante as reuniões são significativos, sendo $23 \%$ dos usuários de Suas de Caxias do Sul e $24 \%$ em Novo Hamburgo. Outro importante aspecto sobre este nível de participação é o baixo percentual da população que fala 

pública.

muito durante uma reunião, representado por apenas 17\% dos usuários de Caxias do Sul e 19\% dos usuários de Novo Hamburgo.

Em relação a participação em nível de consulta, há uma tendência, em ambas as cidades, ainda mais acentuado em Novo Hamburgo, de que a população do SUAS muito pouco é consultada. Muito embora, considerando os índices de quem se diz "sempre convidado" e "as vezes convidado", temos um percentual de $31 \%$ da população do SUAS de Caxias do Sul; Em Novo Hamburgo, de 23\%, conforme tabela 7 abaixo.

Tabela 7. Participação em nível de consulta nas cidades de Caxias do Sul e Novo

\begin{tabular}{|lcc|}
\multicolumn{4}{c}{ Hamburgo (\%) } \\
\hline Quando o Sr. é consultado pelo & Caxias do & Novo \\
governo local? & Sul & Hamburgo \\
Sempre & 7 & 6 \\
Às vezes & 24 & 17 \\
Nunca & 67 & 74 \\
Não sabe & 2 & 3 \\
Total & 100 & 100 \\
\hline
\end{tabular}

Nota. Total: Caxias do Sul N=211 - Novo Hamburgo N=171

Fonte: próprios autores

Em se tratando da participação em nível de elaboração, conforme tabela 8 abaixo, há uma tendência, em ambas as cidades, ainda mais acentuado em Novo Hamburgo, de que a população do SUAS muito pouco é convidada para alguma reunião. Contudo, entre os entrevistados que referem que no último ano foram convidados para alguma reunião, em $27 \%$ correspondem a Caxias do Sul, enquanto em Novo Hamburgo esse percentual caiu para $23 \%$.

Tabela 8. Participação em nível de elaboração nas cidades de Caxias do Sul e Novo Hamburgo (\%)

\begin{tabular}{|lcc|}
\hline No último ano, o Sr. foi convidado & Caxias do Sul & Novo \\
para alguma reunião? & & Hamburgo \\
Sim & 27 & 23 \\
Não & 72,5 & 76 \\
Não sabe & 0,5 & 1 \\
Total & 100 & 100 \\
\hline
\end{tabular}

Nota. Total: Caxias do Sul N=211 - Novo Hamburgo N=171

Fonte: próprios autores

Conforme a tabela 8, a tendência de que no contexto de Caxias do Sul a população tenha sido convidada um pouco mais para algum espaço de consulta pode estar relacionada com a recente pesquisa de Couto (2012) sobre os desafios do controle social do SUAS, em nível nacional. Para a autora, em alguns municípios dos Estados do Rio Grande do Sul e do Paraná, têm-se constado iniciativas da gestão pública na criação de novos espaços e estratégias de participação, tais como as pré-conferências e as ouvidorias. 
Em relação ao nível máximo de participação, denominado de delegação (BORDENAVE, 1983), conforme a tabela 9, observa-se que na cidade de Caxias do Sul, $26 \%$ dos entrevistados sugerem que "sempre é a população que decide" sobre os problemas locais; Em Novo Hamburgo, esse percentual cai um pouco, ficando em $22 \%$.

Tabela 9. Participação em nível de delegação nas cidades de Caxias do Sul e Novo Hamburgo (\%)

\begin{tabular}{|lcc|}
\hline Quem decide sobre os problemas locais? & Caxias do & Novo \\
Sempre a prefeitura & 25 & Hamburgo \\
Às vezes a prefeitura & 21 & 44 \\
Nem a prefeitura, nem a população & 7 & 15 \\
Muito pouco a população & 4 & 8 \\
Às vezes a população & 17 & 1 \\
Sempre a população & 26 & 10 \\
Total & 100 & 22 \\
\hline
\end{tabular}

Nota. Total: Caxias do Sul N=211 - Novo Hamburgo N=171

Fonte: próprios autores

Por outro lado, em Novo Hamburgo, os percentuais indicam uma tendência à centralização do governo nas decisões, onde $44 \%$ da população do SUAS avalia que "sempre é a prefeitura que decide o que fazer". Em Caxias do Sul, essa relação sugere uma perspectiva bem mais democrática, onde o percentual de $25 \%$ apontado para a opção "sempre é a prefeitura que decide".

Conforme referido anteriormente, o capital social existente em uma sociedade pode ser um elemento de sustentação teórica para o desafio da participação no âmbito das políticas públicas, desta forma: existe associação entre o capital social e participação nas cidades em tela? Assim, na sequência, buscaremos analisar em que medida o acúmulo de capital social existente nos municípios de Caxias do Sul e Novo Hamburgo está associado com a qualidade da participação, nas respectivas cidades. 
Tabela 10. Correlação entre Capital social e níveis participação nas cidades de Caxias do Sul (CS) e Novo Hamburgo (NH) (\%)

\begin{tabular}{|c|c|c|c|c|c|}
\hline $\begin{array}{l}\text { Elementos do } \\
\text { Capital social }\end{array}$ & 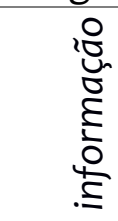 & 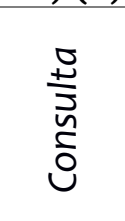 & 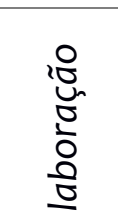 & 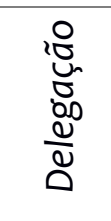 & $\frac{.0}{\frac{2}{\frac{a}{2}}}$ \\
\hline \multirow{2}{*}{ Confiança nos vizinhos } & 0,351 & 0,050 & 0,049 & 0,032 & CS \\
\hline & 0,035 & 0,911 & 0,094 & 0,091 & $\mathrm{NH}$ \\
\hline \multirow{2}{*}{ o problem } & 0,013 & 0,098 & 0,000 & 0,610 & CS \\
\hline & 0,021 & 0,437 & 0,074 & 0,139 & $\mathrm{NH}$ \\
\hline \multirow{2}{*}{$\begin{array}{l}\text { Participação em grupos e assoc. } \\
\text { comunitárias }\end{array}$} & 0,014 & 0,561 & 0,000 & 0,041 & CS \\
\hline & 0,000 & 0,898 & 0,146 & 0,057 & $\mathrm{NH}$ \\
\hline \multirow{2}{*}{ Participação em partidos políticos } & 0,391 & 0,021 & 0,028 & 0,563 & CS \\
\hline & 0,211 & 0,091 & 0,968 & 0,197 & $\mathrm{NH}$ \\
\hline \multirow{2}{*}{ Participação em comícios } & 0,437 & 0,006 & 0,004 & 0,978 & CS \\
\hline & 0,295 & 0,416 & 0,326 & 0,818 & $\mathrm{NH}$ \\
\hline \multirow{2}{*}{ Participação em ass. de moradores } & 0,315 & 0,098 & 0,000 & 0,037 & CS \\
\hline & 0,001 & 0,018 & 0,021 & 0,168 & $\mathrm{NH}$ \\
\hline \multirow{2}{*}{$\begin{array}{l}\text { Participação em Organizações da } \\
\text { Sociedade Civil (OSC) }\end{array}$} & 0,319 & 0,004 & 0,000 & 0,175 & CS \\
\hline & 0,055 & 0,941 & 0,029 & 0,027 & $\mathrm{NH}$ \\
\hline \multirow{2}{*}{ Participação em orçamento participativo ${ }^{9}$} & 0,907 & 0,241 & 0,021 & 0,133 & CS \\
\hline & 0,014 & 0,960 & 0,430 & 0,337 & $\mathrm{NH}$ \\
\hline \multirow{2}{*}{ Participação em man. ou protestos } & 0,005 & 0,115 & 0,303 & 0,004 & CS \\
\hline & 0,125 & 0,480 & 0,987 & 0,139 & $\mathrm{NH}$ \\
\hline
\end{tabular}

Fonte: próprios autores

Constata-se, numa análise comparada entre as cidades, em Caxias do Sul um volume superior de associações entre capital social e participação, sobressaindo-se as variáveis confiança nos vizinhos, participação em grupos e associações comunitárias e participação em associação de moradores. Sobre esta última variável, atrelado o processo de formação sociocultural da cidade de Caxias do Sul, por meio de nossa pesquisa documental realizada, registra-se a existência de 22 associações e clubes, contra 6 em Novo Hamburgo; Somado a isto, a cidade de Caxias do Sul conta com 182 associações de moradores, contra 12 da cidade de Novo Hamburgo.

Aprofundando nossa análise, em relação a participação, encontramos relacionadas dez (10) associações em seu nível de elaboração, oito (8) em nível de informação, e cinco (5) em ambos os níveis de consulta e delegação. Desta forma, para a realidade do SUAS do Rio Grande do Sul estudada por nós, podemos sugerir a relação do capital social e o nível intermediário de participação.

Desta forma, estatisticamente podemos aceitar nossa hipótese alternativa, qual seja, que existe relação positiva entre capital social e a qualidade da

\footnotetext{
9 Em Caxias do Sul, a gestão municipal passou a usar a expressão “Orçamento Comunitário”.
} 
participação no SUAS. Numa perspectiva comparada, em Caxias do Sul, constatamos um volume de 19 associações significativas ( $\leq$ 0,05); em Novo Hamburgo, este volume é bem menor, caindo para 9 associações significativas ( $\leq$ 0,05), indicando um estoque bem maior de capital social na cidade de Caxias do Sul e, consequentemente, uma maior participação nas políticas públicas.

\section{Considerações finais}

Além do importante papel das instituições, das leis e dos desafios orçamentários dos governos, o capital social é também uma variável extremamente relevante na análise da participação nas políticas públicas. Essa relevância ocorre já que o capital social capta fatores mais intangíveis; contudo, fundamentais, que não podem ser negligenciados nas novas discussões sobre as políticas, em especial no seu aspecto de participação. À luz da teoria do capital social, permite-nos olhar a realidade, identificando que os recursos sociais, entre eles a confiança nas pessoas, o envolvimento cívico e a participação em grupos e associações, estão presentes nas instituições que se constituíram eficazes e democráticas. Ademais, o nosso estudo apontou haver uma possível correspondência entre uma sociedade participativa e o seu desenvolvimento econômico. Em Caxias do Sul, onde se verifica um estoque um pouco maior de capital social, contata-se também um PIB per capta maior ( $R \$ 4.738,00$ ), em relação a Novo Hamburgo ( $R \$ 3.399,32)$. Futuras pesquisas, oportunamente, poderiam explorar bem mais a associação entre as variáveis.

Neste sentido, nosso artigo levou-nos a compreender que os elementos do capital social, entre eles, a confiança nas pessoas, a confiança nos vizinhos, a participação em grupos e organizações, a capacidade de resolução de problemas com outras pessoas tem relação positiva com a participação nas políticas públicas. $\mathrm{Na}$ cidade de Caxias do Sul, a análise dos dados permite-nos sugerir que a participação em grupos e associações, em associações de moradores, confiança nos vizinhos e engajamento cívico estão diretamente ligados a qualidade da participação no SUAS. Este último aspecto também se mostrou importante para o contexto da cidade de Novo Hamburgo. Desta forma, a presença destes recursos sociais, com mais "peso" no contexto da cidade de Caxias do Sul, leva-nos, consequentemente, a constatação de um acúmulo maior de capital social nesta cidade, em relação a cidade de Novo Hamburgo.

Neste sentido, a participação em seu nível de informação, no contexto da cidade de Novo Hamburgo, alcança escores melhores. Contudo, quando observamos os níveis mais sofisticados de participação, como consulta, elaboração e delegação, na cidade de Caxias do Sul, alcança-se melhores resultados. Assim, nosso estudo demonstrou que o capital social torna-se uma categoria que pode potencializar os instrumentos de sustentação da democracia, pois, na medida em que cresce o seu estoque, aumenta a participação nas políticas públicas.

\section{REFERÊNCIAS}

ALMEIDA NETO, H. Pesquisa científica na prática. Canoas. EdULBRA. 2008. 
Capital social e a participação dos usuários do SUAS no Rio Grande do Sul: um estudo de política pública.

ARROW, K. J. The limits of organization. London: Norton \& Company, 1974.

ATLAS BRASIL - Atlas do Desenvolvimento Humano no Brasil. Ranking - todo o Brasil (2010). Disponível em: http://atlasbrasil.org.br/2013/pt/ranking/. Acesso em 20 de abr, 2017.

BABBIE, E. Métodos de pesquisa de survey. 3. reimp. Belo Horizonte: UFMG, 2005. 519p.

BANDEIRA, P.S. Algumas hipóteses sobre as causas das diferenças regionais quanto ao capital social no Rio Grande do Sul. In.: SOUZA CORREA, S. M. Capital social e desenvolvimento regional. Santa Cruz do Sul: EDNISC, 2003, 336p.

BAQUERO, M. Qual Democracia para a América Latina: capital social e empoderamento são a resposta? Porto Alegre: Ed. UFRGS, 2013.

BAQUERO, M.; PRÁ J. A democracia brasileira e a cultura política no Rio Grande do Sul. Ed. UFRGS: Porto Alegre, 2007.

BARBETTA, P. Estatística aplicada às ciências sociais. Florianópolis: Edusfc, 2010.

BASTOS, F. A. A inserção da odontologia em quatro municípios em gestão plena do Sistema Municipal do SUS no Rio Grande do Sul: um estudo de avaliação institucional. Tese (Doutorado) - Universidade Luterana do Brasil. Programa de PósGraduação em Odontologia. Canoas, 2008.

BOBBIO, N. (et al). Dicionário de Política. Brasília: UNB. 11.ed, 1998.

BORDENAVE, J. E. D. O que é participação. São Paulo: Brasiliense, 1983.

BOZEMAN, B; PANDEY, S.K. Public management decision making: effects of decision contet. Public Adminitration Review. v.64, n. 5, p. 553-565, 2004.

BRASIL. Presidência da República. Assembleia Legislativa. Constituição da República Federativa do Brasil. Disponível em: http://www.planalto.gov.br /ccivil_03/constituicao/ConstituicaoCompilado.html. 2015.

Ministério do Desenvolvimento Social e Combate a Fome. Secretaria Nacional de Assistência Social. Norma Operacional Básica-NOB SUAS - 2005. Disponível em: https://www.mds.gov.br/webarquivos/arquivo/assistencia_social/nob_suas.pdf.

CARAGNATO, L. Presença e contribuição dos afro-descendentes no município de Caxias do Sul - 1875 a 1950. MÉTIS: história \& cultura - v. 9, n. 17, p. 201-215, jan./jun, 2010.

COLE, G. D. H. Social Theory. Londres: Methuen, 1920. 
DOWBOR, L. A reprodução Social Vol. III: descentralização e participação - as novas tendências. Rio de Janeiro: Vozes, 2003.

DYE, R. T. Mapeamento dos módulos de análise de políticas públicas. In.: HEIDEMANN, F; SALM J (org.). Políticas públicas e desenvolvimento: bases epistemológicas e modelos de análise. 3.ed. Brasília: UNB, 2014.

FERRAZ, F. (2016). Brasil: a cultura política de uma democracia mal resolvida. Porto Alegre: Ad2000, 2016.

. A Infraestrutura social da democracia americana. Porto Alegre: PUCRS, 1977.

FUKUYAMA, F. Confiança: as virtudes sociais e a criação da prosperidade. Ed. Rocco: Rio de Janeiro, 1996.

GERTZ, R. Colonização: segunda fase. In: CARELI, Sandra da Silva; KNIERIM, Luiz Claudio (org.). Releituras da História do Rio Grande do Sul. Porto Alegre, CORAG, 2011.

GIDDENS, A. (org). O debate global sobre a terceira via. São Paulo: UNESP, 2007.

GOHN, M. da G. Conselhos gestores e participação sociopolítica. São Paulo: Ed. Cortez, 2011.

GUSTAFSSON, G. Symbolic and pseudo policies as responses to diffusion of Power. Policy sciences. v. 5, n. 3, p. 269-287, 1983.

HERÉDIA, V. B. M. O mito do imigrante no imaginário da cultura. MÉTIS: história \& cultura - v. 4, n. 8, p. 233-244, jul./dez, 2005.

INGLEHART, R. Modernización y posmodernización: el cambio cultural, económico y político en 43 sociedades. Madrid: Centro de Investigaciones Sociológicas/Siglo Veintiuno, 2001.

INSTITUTO BRASILEIRO DE GEOGRAFIA E ESTATÍSCA- IBGE. Caracterização dos municípios do Estado do Rio Grande do Sul. Disponível em:

https://cidades.ibge.gov.br/brasil/rs/panorama. Acesso em mai, 2012.

KHAN, A. S.; SILVA, L. M. R. Avaliação do Projeto São José no Estado do Ceará: Estudo de Caso. UFC/CCA /DEA, Fortaleza, Ceará, 2012.

LAHERA, E. Introducción a las políticas públicas. Chile: Fondo de Cultura Económica, 2012. 
Capital social e a participação dos usuários do SUAS no Rio Grande do Sul: um estudo de política pública.

LOTTA, G. Teoria e análise sobre implantação de políticas públicas no Brasil. Brasília: ENAP, 2019, 324p.

LOWI, T. J. American Business, public policy, case studies, and political theory. World Politics, v. 16, n. 4, p. 667-715, 1964.

MARQUES, D; SANTOS, E; KUHN JUNIOR, N. Os desafios do controle social do (suas) e a subcidadania brasileira: o caso de Novo Hamburgo. Revista Brasileira de Gestão e Desenvolvimento Regional, Taubaté, SP, v. 12, n. 2, p. 116-137, mai-ago, 2016.

MEIRELLES, M. O uso do SPSS (Statistical Package for the Social Sciences) na Ciência Política: uma breve introdução. Revista Pensamento Plural, Pelotas, n 15, p. 65-91, jan-jun, 2012.

MICELI, S (org.) O que ler na ciência social brasileira (1970-1995). São Paulo: Ed. Sumaré: AMPOCS, Brasília: DF, 1999.

MILL, S. O governo representativo. São Paulo: Escala, 2001.

MONASTEIRO, L. M. Medindo o capital social: uma análise das regiões do Rio Grande do Sul. In.: SOUZA CORREA, S. M. Capital social e desenvolvimento regional. Santa Cruz do Sul: EDNISC, 2003, 336p.

NOGUEIRA, V. M. R. Avaliação e monitoramento de políticas e programas sociais revendo conceitos básicos. Revista Katálysis, Santa Catarina vol.5, n.2, p.141 a 152, Jul/dez, 2012.

NORTH, D. Institutions, institutional change and economic performance. EUA: Cambridge University Press, 2007.

OLSON, M. A lógica da ação coletiva: os benefícios públicos e uma teoria dos grupos sociais. São Paulo: EDUSP, 1999.

PASE, H. L. Capital social e desenvolvimento: a experiência do Rio Grande do Sul. Pelotas: Ed.UFPEL, 2016.

PESAVENTO, S. J. História do Rio Grande do Sul. Porto Alegre: Mercado Aberto, 1980.

PROGRAMA DAS NAÇÕES UNIDAS PARA O DESENVOLVIMENTO-PNUD. Relatório do Desenvolvimento Humano Brasileiro 2009-2010. Disponível em: http://www.pnud.org.br/Noticia.aspx?id=4175. Acesso em mai, 2015.

PUTNAM, R. Comunidade e democracia: a experiência da Itália moderna. São Paulo: FGV, 2000.

RIBEIRO, I; FERNANDES, E; RIBEIRO, H. A importância do capital social para o desenvolvimento de uma região. Revista RURIS, v. 6, nº 1, mar, 2012. 
ROUSSEAU, J. The social contract. New York: Penguin Books, 1968.

SANTOS, M. de O; ZANINI, M. C. C. Especificidades da Identidade de descendentes de italianos no sul do Brasil: breve análise das regiões de Caxias do Sul e Santa Maria. Revista Antropolítica, Niterói, n. 27, p. 21-41, 2009.

SANTOS, E. Democracia e desenvolvimento: desafios da sociedade gaúcha. ljuí: Edjuí, 2013.

SANTOS E.; NUNES, M. F. Capital Social e políticas públicas: um estudo comparado no Vale do Rio dos Sinos. Revista de Administração Pública, Rio de Janeiro, v. 50, n.1, p.129-149, jan.fev, 2016.

SECCHI, L. Políticas Públicas: conceitos, esquemas de análise, casos práticos. São Paulo: Cengage Learning, 2014.

SOUZA, C._Políticas públicas: uma revisão da literatura. Revista Sociologias, n.16, pp.20-45, 2006.

STASSEN, J.F. Exclusion and participation: can the excluded become able to participate? Belgium: Université de Liége, 1999.

SCHÜTZ, M.M.E. Novo Hamburgo: sua história, sua gente. Porto Alegre: Pollott, 1976.

SZRETER S. Social Capital: critical perspectives. EUA: OXFORD University Press, 1999.

TABELLINI, G. Culture and institutions: economic development in the regions of Europe. EUA: CESIFO, 2005.

TOCQUEVILLE, A. A democracia na América. Tradução, prefácio e notas: Neil Ribeiro da Silva. 2. ed. Belo Horizonte: Itatiaia; São Paulo: Edusp, 1998.

WITTMANN, M. L.; RAMOS, M. P. (Org.) Desenvolvimento regional: Capital social, redes e planejamento.Santa Cruz do Sul: EDUNISC, 2004.

WILSON, J, Q. American goverment: institutions and policies. Lexington: Heart \& Co. 1983.

Douglas Marques. Doutor em Diversidade Cultural e Inclusão Social. Universidade Estadual de Maringá (UEM). Professor. E-mail: douglas.sersocial@gmail.com.

Everton Rodrigo Santos. Doutor em Ciência Política. Universidade Feevale. Professor. E-mail: evertons@feevale.br. 
Como citar: MARQUES, Douglas; SANTOS, Everton Rodrigo. Capital social e a participação dos usuários do SUAS no Rio Grande do Sul: um estudo de política pública.. Redes (St. Cruz Sul, Online), Santa Cruz do Sul, v. 25, p. 1973-1995, nov. 2020. ISSN 1982-6745. doi:https://doi.org/10.17058/redes.v25i4.14078.

\section{CONTRIBUIÇÃO DE CADA AUTOR}

a. Fundamentação teórico-conceitual e problematização: Douglas Marques e Everton R. Santos.

b. Pesquisa de dados e análise estatística: Douglas Marques e Everton R. Santos.

c. Elaboração de figuras e tabelas: Douglas Marques e Everton R. Santos.

d. Elaboração e redação do texto: Douglas Marques e Everton R. Santos.

e. Fotos: não se aplica.

F. Seleção das referências bibliográficas: Douglas Marques e Everton R. Santos. 